\title{
Crescimento de cultivares de Ipomoea batatas oriundas de rebentos produzidas de forma convencional e in vitro
}

\section{Growth of Ipomoea batatas cultivars originated from conventionally or in vitro produced sprouts}

\author{
Francisco A. A. Câmara ${ }^{1,+}$, Leilson C. Grangeiroํㅜㄹ Jeferson L. D. Dombroski ${ }^{1}$, \\ Rômulo M.O. Freitas ${ }^{3, *}$, Francisco C. L. Freitas ${ }^{4}$ e Maria Z. Negreiros ${ }^{1}$ \\ ${ }_{1}^{1}$ Universidade Federal Rural do Semi-Árido, Departamento de Ciências Vegetais, CEP 59625-900, Mossoró, Rio Grande do Norte, Brasil \\ ${ }^{3}$ Instituto Federal de Educação, Ciência e Tecnologia Baiano, Campus Valença, CEP 45400-000, Valença, Bahia, Brasil \\ ${ }^{4}$ Departamento de Fitotecnia, Centro de Ciências Agrárias, Universidade Federal de Viçosa CEP 36570-000, Viçosa, MG, Brasil \\ 'In memoriam \\ (*E-mail: romulomagno_23@hotmail.com) \\ http://dx.doi.org/10.19084/RCA15019
}

Recebido/Received: 2015.02 .28

Recebido em versão revista/received in revised form: 2016.01.27

Aceite/accepted: 2016.12 .09

\section{R E S U M O}

O presente trabalho teve como objetivo avaliar o crescimento e desempenho agronómico de cultivares de batata-doce oriundas de rebentos produzidos de forma convencional e in vitro. O delineamento experimental utilizado foi o de blocos casualizados, em esquema fatorial 5×2, com quatro repetições. Os tratamentos consistiram da combinação de cinco cultivares de batata-doce ('ESAM 1', ‘ESAM 2', 'ESAM 3', ‘Branca do Rio de Janeiro' e 'Califórnia') e duas formas de propagação (convencional e in vitro). Para a análise de crescimento foram colhidas amostras de plantas aos 40, 60, 80, 100 e 120 dias após a plantação, das quais foram determinadas a massa seca de raiz tuberosa, total e área foliar. Foram calculados os índices fisiológicos: taxa de crescimento absoluto e relativo, índice de área foliar e taxa de assimilação líquida. Foi verificada interação significativa entre cultivares, formas de propagação e épocas para todas as variáveis. Os maiores valores de área foliar foram observados nas plantas oriundas de cultura de tecidos. A cultivar 'ESAM 2' produziu uma maior quantidade de massa seca total, taxa de crescimento absoluto e massa seca de raízes tuberosas.

Palavras-chave: análise do crescimento, cultura de tecidos, batata-doce.

\begin{abstract}
A B S T R A C T
This work had the objective of analyzing the growth and agronomic behavior of sweet potato cultivars originated from conventionally or in vitro produced sprouts. The experimental design was a $5 \times 2$ full factorial in randomized complete blocks with four replicates. The treatments were five sweet potato cultivars ('ESAM 1', 'ESAM 2', 'ESAM 3', 'Branca do Rio de Janeiro' e 'Califórnia') and two propagation methods (conventional and in vitro). For the growth analysis, plant were collected at 40,60, 80, 100 and 120 days after planting, from which was measured the plant dry mass, the tuberous root dry mass, and the leaf area. The following physiological indexes were calculated: absolute and relative growth rates, leaf area index and net assimilatory rate. A significant interaction among cultivars, propagation forms and evaluation time for all variables was observed. The highest values were obtained for the plants originated from in vitro culture. Cultivar 'ESAM 2' exhibited a higher plant dry mass, absolute growth rate and tuberous roots dry mass.
\end{abstract}

Keywords: growth analysis, tissue culture, sweet potato. 


\section{INTRODUÇÃO}

A batata-doce [Ipomoea batatas (L.) Lam.] é uma cultura de grande importância económico-social, participando do suprimento de calorias e minerais na alimentação humana, principalmente das populações de baixa rendimento. No contexto mundial, 90\% da produção concentra-se na Ásia, $5 \%$ na África e $5 \%$ no resto do mundo. A China é o maior produtor, com produção de ca. 100 milhões de toneladas anuais (Silva et al., 2004). No Brasil, a batata-doce é cultivada em todas as regiões embora esteja mais presente nas regiões Sul e Nordeste. Numa área de 41.802 ha a produção tem sido de $495.182 \mathrm{t}$ com um rendimento de $11,846 \mathrm{t} \mathrm{ha}^{-1}$ (IBGE, 2010).

Essa cultura é propagada através de rebentos, ou mesmo de raízes tuberosas obtidas quase sempre na época da colheita, o que contribui para um baixo rendimento. Esse método tradicional de propagação provoca, ao longo do tempo, problemas como disseminação de pragas e doenças, principalmente aquelas provocadas por organismos sistémicos, dificuldade de eliminação de vírus e irregularidade nas plantações. De forma alternativa, a micropropação através da cultura de meristemas in vitro (Madeira et al., 2005; Magalhães et al., 2006) tem possibilitado a obtenção de plantações livres de vírus e de outros agentes patogénicos, viabilizando a produção de grande número de plantas que podem ser utilizadas para a formação de matrizes com todo o potencial genético.

Segundo Aumonde et al. (2011), a partir do estudo de variáveis de crescimento é possível conhecer o comportamento vegetal sob diferentes condições. A análise de crescimento descreve as mudanças na produção vegetal em função do tempo, o que não é possível com o simples registro do rendimento. Os índices determinados na análise de crescimento indicam a capacidade do sistema assimilatório das plantas em sintetizar (fonte), através das folhas, e alocar a matéria orgânica nos diversos órgãos (drenos), como estruturas reprodutivas que dependem da fotossíntese, respiração e translocação de fotoassimilados (Larcher, 2004).

Neste contexto, o presente trabalho teve como objetivo avaliar o crescimento de cultivares de batata-doce, oriundas de rebentos de plantas obtidas do cultivo em campo e in vitro, nas condições climáticas do semiárido nordestino.

\section{MATERIAL E MÉTODOS}

\section{Local e delineamento experimental}

O estudo foi conduzido no Laboratório de Cultura de Tecidos Vegetais e na horta didática do Departamento de Ciências Vegetais da Universidade Federal Rural do Semiárido UFERSA, em Mossoró-RN, no período de agosto a dezembro de 2008. Da área experimental foram retiradas amostras simples de solo na camada de 0 a $20 \mathrm{~cm}$ para compor a amostra composta, utilizando-se um trado holandês e submetida à análise química, cujos resultados foram: $\mathrm{pH}\left(\mathrm{H}_{2} \mathrm{O}\right)$ de 7,30, $\mathrm{P}$ de 204,42 $\mathrm{mg} \mathrm{m}^{-3}$, $\mathrm{K}$ de 0,15, Ca 4,40, $\mathrm{Mg}$ de 2,50, Na de 0,23 e Al de $0,0 \mathrm{cmol}_{\mathrm{c}} \mathrm{dm}^{-3}$.

O delineamento experimental consistiu em blocos casualizados completos, fatorial $2 \times 5$, com quatro repetições. Os tratamentos foram constituídos pela combinação de dois métodos de propagação (convencional e in vitro) e cinco cultivares ('ESAM 1', 'ESAM 2', 'ESAM 3', ‘Branca do Rio de Janeiro' e 'Califórnia'). A unidade experimental foi composta por três linhas de plantas de $4,0 \mathrm{~m}$ de comprimento, espaçadas de $1,0 \mathrm{~m}$ e $0,4 \mathrm{~m}$ entre plantas, sendo utilizada como área útil a linha central, descartando-se uma planta de cada extremidade, correspondendo a uma área total e útil de $12 \mathrm{e}$ $3,2 \mathrm{~m}^{2}$, respectivamente.

\section{Fase de laboratório e estufa}

Os rebentos das cultivares avaliadas foram provenientes da coleção de batata-doce instalada na horta didática do Departamento de Ciências Vegetais da UFERSA. Após a seleção, os rebentos apicais, de $40 \mathrm{~cm}$, com oito a dez nós apresentando bom aspecto fitossanitário, foram plantadas, com três a quatro nós enterrados, em vasos contendo uma mistura de esterco de bovino fermentado e solo na proporção de 2:1 em estufa. Foram removidas as partes apicais dos rebentos em crescimento e oito dias depois foram retirados segmentos nodais, com aproximadamente $20 \mathrm{~mm}$ de comprimento, contendo uma gema lateral. Esses rebentos, contendo a gema 
apical e a lateral, foram devidamente acondicionados em placas de Petri, previamente humedecidos e esterilizados, e posteriormente levados para o laboratório, onde sofreram desinfestação.

A remoção dos meristemas foi realizada ao microscópio estereoscópico, em uma câmara de fluxo laminar estéril. Foi realizada a excisão dos ápices, com aproximadamente 0,4 a $0,6 \mathrm{~mm}$, de cada cultivar e transferidos para tubos de ensaio, contendo $10 \mathrm{~mL}$ de meio de cultura (Oliveira et al., 2008). O meio nutritivo básico consistiu de macro e micronutrientes, de acordo com Murashige e Skoog (1962). A cultura foi conduzida em sala de crescimento a uma temperatura de $25 \pm 3^{\circ} \mathrm{C}$ e fotoperíodo de $16 \mathrm{~h}$ luz/dia com intensidade luminosa e irradiância de aproximadamente $30 \mu \mathrm{mol} \mathrm{m}^{-2} \mathrm{~s}^{-1}$. O material foi replicado quando apresentava três ou mais gemas, até se obter um número suficiente de rebentos enraizados para a instalação das fases posteriores do estudo.

A fase de aclimatização iniciou com a abertura dos tubos de ensaio mediante a realização de furos nos filmes que protegiam os mesmos, perfurados gradativamente com agulhas para favorecer as trocas gasosas entre a plântula e o novo ambiente, permanecendo na sala de crescimento por oito dias. Em seguida, as plântulas foram retiradas dos frascos, lavadas e transferidas para bandejas de polietileno expandido contendo 128 células, preenchidas com substrato comercial e levadas para a estufa (temperatura de $28 \pm 3^{\circ} \mathrm{C}$ e humidade relativa do ar média de aproximadamente $60 \%$ ) onde permaneceram por mais oito dias. Então, as plantas foram transferidas para sacos plásticos com capacidade de $5 \mathrm{~kg}$, contendo mistura de solo e adubo orgânico (esterco de bovino curtido) na proporção 2:1, permanecendo por 80 dias, quando foram retirados rebentos apicais com tamanho de aproximadamente $40 \mathrm{~cm}$ de comprimento, contendo de oito a 10 entrenós, que foram levados para o campo, juntamente com os rebentos das mesmas cultivares, multiplicadas na horta didática, exatamente no mesmo período de tempo.

\section{Fase de campo}

No campo, a plantação foi realizada utilizando rebentos apicais de aproximadamente $40 \mathrm{~cm}$ de comprimento (com folhas, contendo de oito a 10 nós, como já foi referido), colhidos no dia anterior das plantas matrizes, multiplicadas in vitro e no campo e mantidas à sombra. O espaçamento utilizado foi $1,0 \mathrm{~m} \times 0,4 \mathrm{~m}$, sendo colocado em cada cova apenas um rebento, com três a quatro nós enterrados, a uma profundidade de aproximadamente $10 \mathrm{~cm}$. A adubação de cobertura foi realizada aos 30 dias após a plantação (DAP), com $20 \mathrm{~kg} \mathrm{ha}^{-1}$ de azoto, $20 \mathrm{~kg} \mathrm{ha}^{-1}$ de fósforo e $20 \mathrm{~kg} \mathrm{ha}^{-1}$ de potássio, nas formas de ureia, superfosfato simples e cloreto de potássio, respectivamente (Cavalcanti, 1998). As irrigações foram diárias, empregando-se microaspersores com dotação de $40 \mathrm{~L} \mathrm{~h}^{-1}$, sendo que ao longo do ciclo foi aplicada uma lâmina de água de aproximadamente $450 \mathrm{~mm}$.

Como operações culturais foram realizadas mondas manuais aos 25 e 55 dias, para manter a cultura livre da competição com plantas daninhas, bem como amontoa para proteger as raízes contra a incidência de luz e manter a formação dos leirões.

\section{Variáveis analisadas}

Durante o ciclo da cultura foram realizadas amostragens aos 40, 60, 80, 100 e 120 DAP. Em cada amostragem foi colhida uma planta por parcela e separada em folhas, caules e raízes. A área foliar foi determinada usando o método do disco (Souza et al., 2012) corrigido. Para a correção, os valores obtidos pelo método do disco foram multiplicados por uma constante característica de cada cultivar. Essa constante foi determinada a partir da análise de regressão entre os valores de área de uma amostra de 15 folhas de cada cultivar, obtido pelo método do disco e os valores de área determinados após análise das imagens obtidas com auxílio de um digitalizador de mesa das mesmas folhas. Para a determinação das áreas por análise de imagens foi utilizado o programa de computador Sigmascan ${ }^{\circledR}$ (SPSS). Para determinação da massa seca, a planta foi colocada em estufa com circulação forçada de ar à temperatura de $65^{\circ} \mathrm{C}$, até atingir massa constante.

Os valores de massa seca total e massa seca de raízes foram ajustados segundo o modelo logístico conforme descrito por Yin et al. (2003), sendo as 
constantes estimadas pelo método de Levemberg-Marquardt. Para representar os valores de área foliar foi escolhida a curva de Gauss.

Com os valores de área foliar (AF), massa seca total (MST) e os períodos de amostragem ( $t$, dias) foram determinados (Evans, 1972; Benincasa, 2003): índice de área foliar (IAF); taxa de crescimento absoluto (TCA); taxa de crescimento relativo (TCR); taxa de assimilação líquida (TAL), utilizando-se as seguintes fórmulas $\mathrm{IAF}=\mathrm{AF} / \mathrm{espa}$ çamento; $\mathrm{TCA}=\mathrm{dMS} / \mathrm{dT}$, $\left(\right.$ g.dia $\left.{ }^{-1}\right) ; \mathrm{TCR}=(\mathrm{dMS} / \mathrm{dt}) \times(1 /$ $\mathrm{MS}),\left(\mathrm{g} \cdot \mathrm{g}^{-1} \cdot \mathrm{t}^{-1}\right) ; \mathrm{TAL}=\mathrm{dMS} / \mathrm{dt} \times 1 / \mathrm{AF},\left(\mathrm{g} \cdot \mathrm{m}^{-2} \cdot \mathrm{dia}^{-1}\right)$.

\section{Análise dos dados}

Os resultados obtidos foram submetidos a análises de variância, com os quadrados médios comparados pelo teste $\mathrm{F}$ a $5 \%$ de probabilidade. No ajuste das equações de regressão foi utilizado o software Table Curve 5.0.

\section{RESULTADOS E DISCUSSÃO}

Houve interação significativa entre cultivares, forma de propagação e época para as características massa seca total, área foliar, índice de área foliar, taxa de crescimento absoluto, taxa de crescimento relativo, taxa de assimilação líquida e massa seca de raiz tuberosa.

A massa seca total seguiu, independentemente da forma de propagação, o padrão logístico de crescimento. A acumulação de massa seca total foi crescente até os 120 dias após a plantação (DAP), sendo as plantas propagadas in vitro superiores às convencionais (Figura 1A e 1B). Segundo Figueiredo (1993), o padrão de crescimento da batata-doce segue a tendência sigmoidal, com três fases distintas: uma inicial, anterior à formação de raízes tuberosas, quando o crescimento é lento; outra intermediária, que vai do início da formação das raízes tuberosas até próximo ao ponto de colheita, quando o crescimento é acelerado; e outra final, quando as raízes estão no ponto de colheita, onde o acréscimo na massa seca é lento e as curvas aproximam-se de um patamar. A Figura 1 ilustra essas três fases (com exceção para a cultivar 'Califórnia' propagada de forma convencional), embora a fase inicial não esteja bem nítida devido à amostragem se ter iniciado aos 40 DAP.

Comportamento semelhante foi observado por Conceição et al. (2005), em estudo da análise de crescimento de duas cultivares de batata-doce. Segundo os autores, as cultivares apresentaram tendência logística com relação à massa seca total, com máximos de 1,141 e 1,405 $\mathrm{g} \mathrm{m}^{-2}$ para as cultivares 'Abóbora' e 'Da Costa', respectivamente, atingidos aos 150 dias após o transplante. Echer et al. (2009) observaram crescimento linear positivo da massa seca de raízes e folhas da cultivar 'Canadense' até os 115 dias após a transplantação (DAT). Entre 115 e 130 DAT, houve um forte crescimento da massa seca de raízes tuberosas, reflexo da translocação e da acumulação de nutrientes, mas após esse período houve diminuição na massa seca das raízes tuberosas. Esse fato se explica pelo ciclo perene da cultura, pois nessa terceira fase a planta redireciona os fotoassimilados e investe no crescimento vegetativo.

Analisando o comportamento das cultivares quanto à propagação, verifica-se que a cultivar 'ESAM 2' produziu uma maior quantidade de massa seca total, seguida da 'Branca do Rio de Janeiro', 'Califórnia', 'ESAM 3' e 'ESAM 1'. As produções máximas de massa seca total foram, respectivamente, na mesma ordem das cultivares acima, de $302,21,276,17,239,56,220,17$ e 172,46 g planta $^{-1}$ para a propagação convencional e de 396,29, 363,05, $322,95,311,61$ e 322,12 g planta $^{-1}$ para propagação in vitro. A diferença em favor da segunda forma de propagação foi de 31,13, 31,46, 34,80, 41,53 e 86,78\% (Figura 1). Em alho, o crescimento da parte aérea, expresso pela altura e número de folhas/planta, e do bolbo, de acordo com a razão bolbar, em plantas oriundas da cultura de tecidos, mostrou-se superior ao das plantas convencionais (Resende et al., 2000).

Medeiros et al. (1990), trabalhando com as cultivares de batata-doce 'Coquinho' e 'Princesa', obtiveram mais matéria seca em todas as partes da planta, bem como uma maior área foliar na cultivar 'Coquinho' e explicam que a ausência de lóbulos profundos pode ter influenciado este aumento, já que a cv. 'Princesa' tem o limbo dividido em cinco lóbulos profundos. 

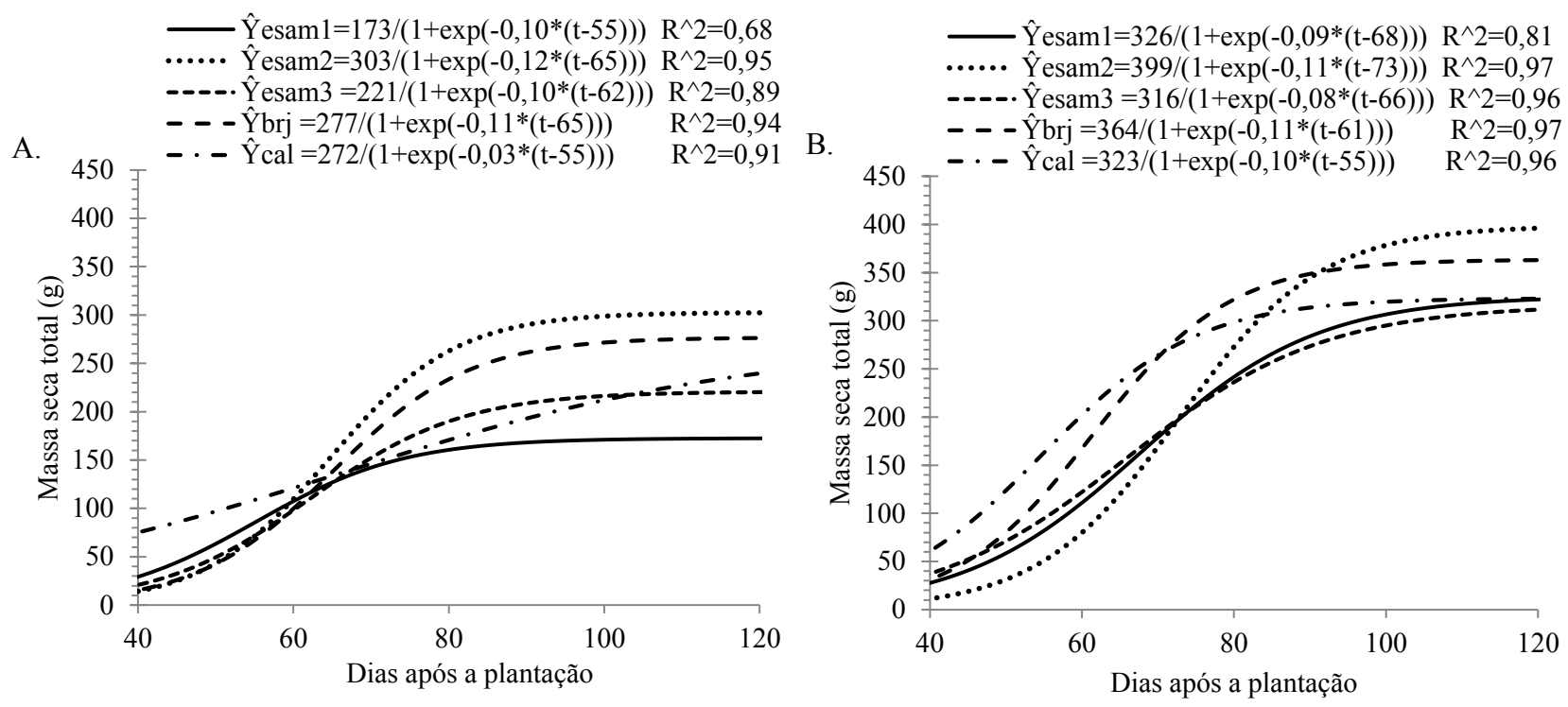

Figura 1 - Massa seca total em batata-doce plantada, oriundas de ramas produzidas de forma convencional (A) e de cultivo in vitro (B), cultivares 'ESAM 1', 'ESAM 2', 'ESAM 3', 'Branca do Rio de Janeiro' e 'Califórnia'.

Constata-se que, nos dois métodos de propagação, a cultivar 'ESAM 2' apresentava maior produção de biomassa total já na colheita aos 100 DAP, com maior aptidão para uso em alimentação animal.

Os dados de massa seca das raízes tuberosas foram ajustados segundo o modelo logístico (Yin et al., 2003). Apesar do comportamento da cultivar 'Califórnia', oriunda do campo (Figura 2A), não permitir a avaliação adequada da produção máxima e da data para a produção máxima, segundo o modelo logístico, preferiu-se usá-lo, pois houve uma correspondência considerada adequada com os valores medidos $\left(\mathrm{r}^{2}=0,91\right)$. O mesmo modelo foi considerado adequado para ajuste dos dados de matéria seca total da planta e para os dados de matéria seca de raízes tuberosas das demais cultivares e da própria, quando advinda de propagação in vitro (Figura $2 \mathrm{~B}$ ).

Para todos os casos, houve tendência de aumento da produção de raízes tuberosas (massa seca) nas plantas oriundas de micropropagação, com aumento significativo para a cultivar 'Califórnia'. Nas plantas oriundas do campo, a produção da cultivar 'Califórnia' foi inferior à da 'ESAM 2', sendo a última semelhante às demais cultivares. Maior produção de raízes tuberosas de batata-doce também foram verificadas por Silva et al. (1991), quando propagadas por cultura de tecidos.
Nesse estudo verificaram-se ganhos percentuais até $108,1 \%$ em relação a plantas propagadas pelo método convencional.

Verificou-se uma tendência de maior precocidade de produção nas plantas oriundas do campo, exceto para a cultivar 'Branca do Rio de Janeiro'. Essa precocidade pode ter sido devida ao maior vigor vegetativo das plantas oriundas in vitro, pois é fato conhecido que, em batata-doce, condições ambientais que propiciam maior vigor vegetativo afetam a formação de raízes tuberosas (Medeiros et al., 1990).

Os valores de área foliar apresentam tendência de crescimento até os 60 ou 80 dias, decrescendo a seguir (Figura 3A e 3B). Essa redução da área foliar é uma característica bem conhecida em batata-doce (Medeiros et al., 1990; Conceição et al., 2005) e comum em plantas com crescimento determinado (Evans, 1972), sendo provocada tanto pela redução da emissão de folhas como pela senescência foliar. Essa alteração do padrão de crescimento está associada com o início da formação das raízes tuberosas, tendo sido relacionada com a modificação do padrão de dreno da planta. Na fase de crescimento da área foliar, as folhas representam um dreno muito importante recebendo grande parte dos fotoassimilados (Medeiros et al., 1990). Quando a tuberização é prioritária as raízes constituem o 

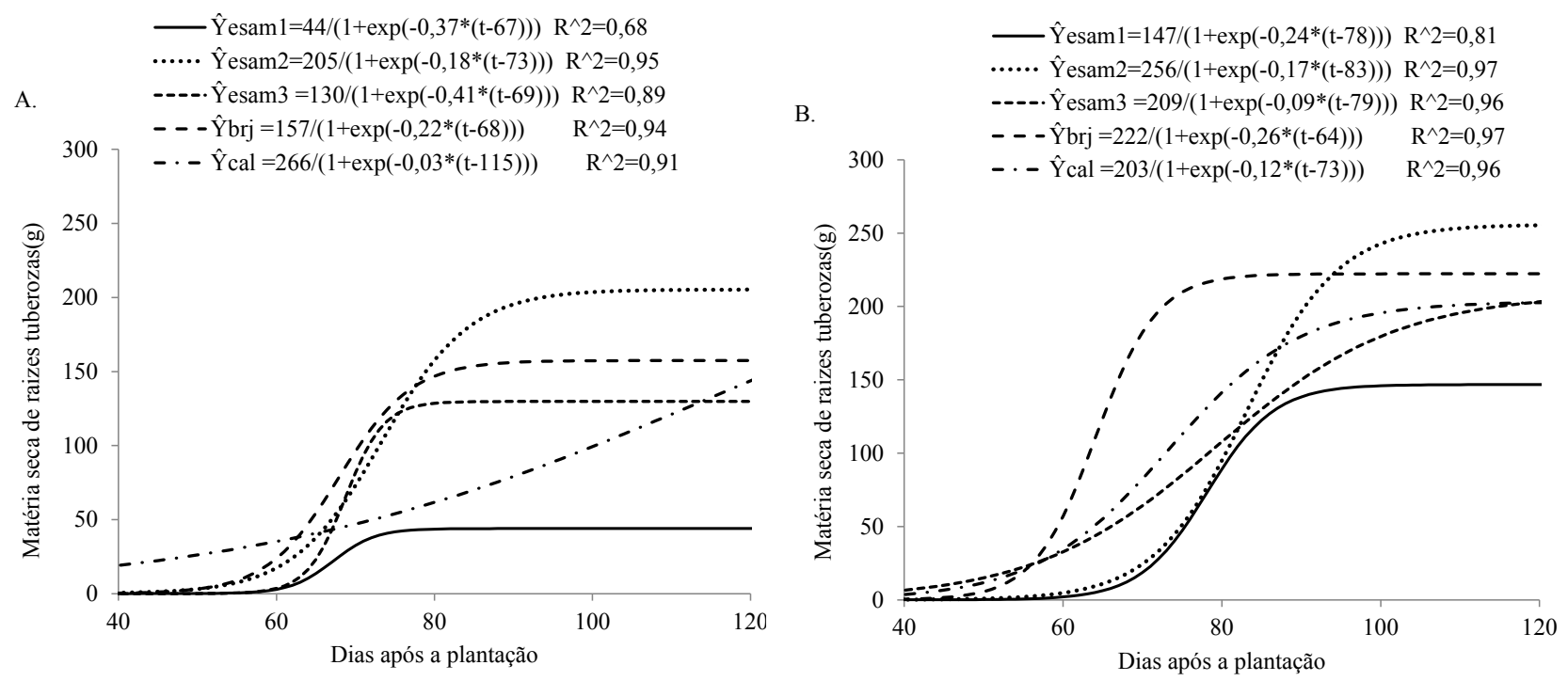

Figura 2 - Massa seca de raízes tuberosas em batata-doce proveniente da multiplicação convencional (A) e cultivo in vitro (B), cultivares 'ESAM 1', 'ESAM 2', 'ESAM 3', 'Branca do Rio de Janeiro' e 'Califórnia’.
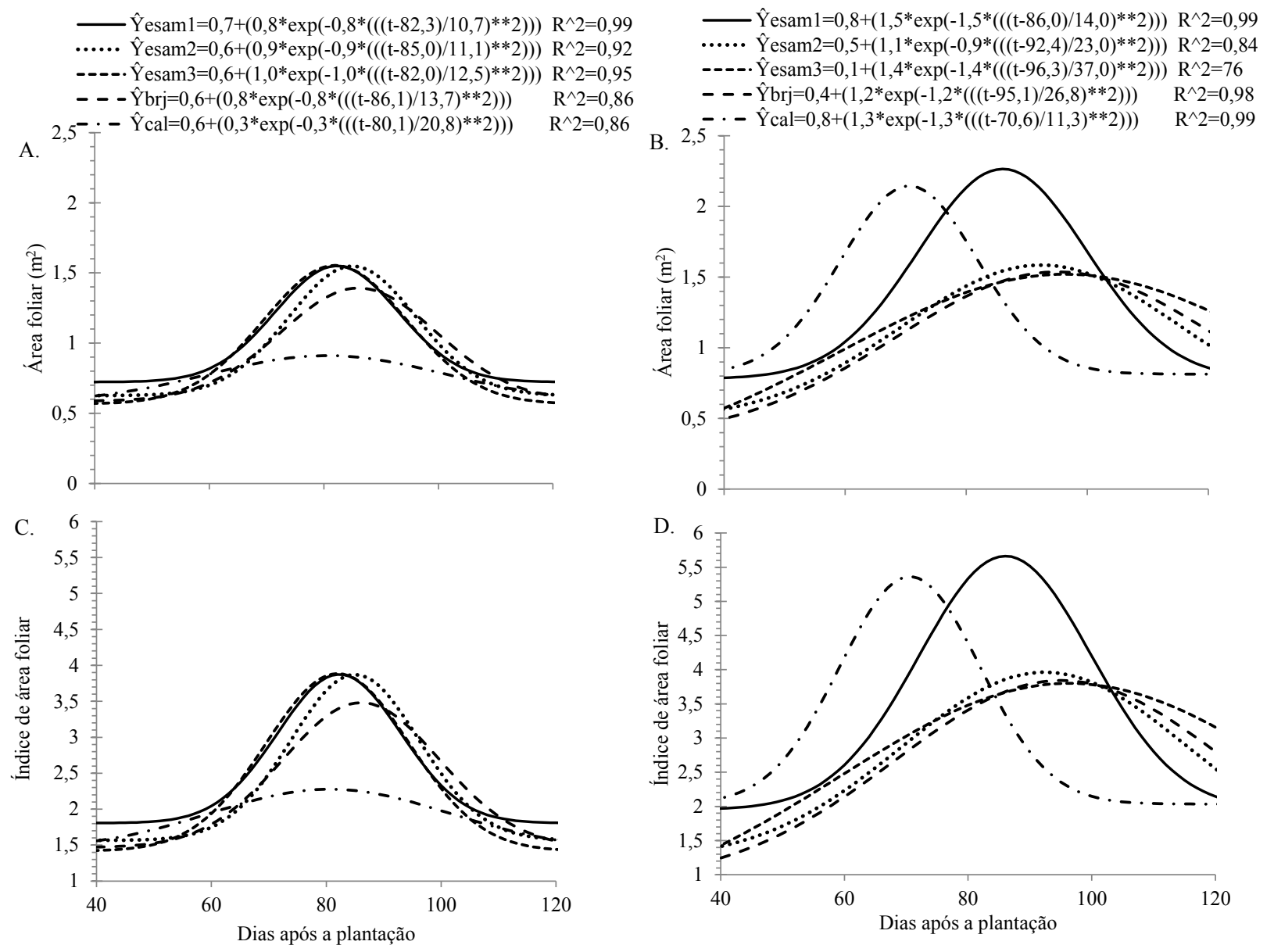

Figura 3 - Área foliar (A e B) e índice de área foliar (C e D) em batata-doce proveniente da multiplicação convencional (A e C) e cultivo in vitro (B e D), cultivares 'ESAM 1', 'ESAM 2', 'ESAM 3', 'Branca do Rio de Janeiro' e 'Califórnia'. 
dreno mais importante, impedindo a formação de novas folhas e mesmo a manutenção das folhas mais velhas (Conceição et al., 2005).

Não foram observadas diferenças nas áreas foliares médias entre as cultivares, tanto para plantas com origem no campo como para as oriundas de cultura de tecidos. Os resultados de área foliar máxima obtidos para as plantas com origem no campo são um pouco superiores aos obtidos por Medeiros et al. (1990) para as cultivares 'Coquinho' e 'Princesa', em Brasília-DF, e bastante inferiores aos apresentados por Conceição et al. (2005). Os altos valores apresentados por estes últimos autores, além das diferenças clonais, podem ter sido devidos às diferentes condições ambientais, estimulando o crescimento vegetativo daquelas plantas. Todavia, os valores máximos obtidos no presente estudo foram superiores aos apresentados por Queiroga et al. (2007) para as cultivares 'ESAM 1', 'ESAM 2' e 'ESAM 3' (0,32, 0,27 e 0,38 m², respectivamente). Os motivos dessas diferenças não são conhecidos.

Os maiores valores de áreas foliares e índices de área foliar obtidos nas plantas oriundas de micropropagação (Figura 3B e 3D) foram devidos inicialmente a um maior investimento na produção de folhas ou maior duração das mesmas (efeito primário). Esse aumento da área foliar, por sua vez, provocou maior auto-sombreamento nesse tratamento. Em função disso, registou-se uma tendência das folhas produzidas apresentarem maiores áreas (efeito secundário) e menor espessura (Larcher, 2004), ou seja, maior área foliar específica.

As taxas de crescimento absoluto (TCA) das plantas multiplicadas in vitro foram superiores às plantas multiplicadas de forma convencional, para todas as cultivares (Figura 4A e 4B). De modo geral, a TCA assumiu valores iniciais baixos, passando por uma fase de crescimento contínuo até atingir o ponto de máximo (variável com as cultivares e forma de propagação), decrescendo posteriormente na fase final do ciclo.

$\mathrm{Na}$ propagação convencional, a TCA confirma o comportamento diferenciado na acumulação de massa seca entre as cultivares, com valores máximos encontrados de 9,27 $\mathrm{g}_{\text {planta }}{ }^{-1}$ dia $^{-1}$ para a 'ESAM 2'; 7,81 g planta-1 dia $^{-1}$ para a 'Branca do Rio de Janeiro'; 5,63 g planta $^{-1} \cdot$ dia $^{-1}$ para a
'ESAM 3'; 4,50 g planta $^{-1}$ dia $^{-1}$ para a 'ESAM 1' e 2,52 g planta ${ }^{-1}$ dia $^{-1}$ para a 'Califórnia', atingidos, respectivamente, aos 65, 65, 63, 55 e 66 DAP (Figura 4A). Verifica-se que o decréscimo da TCA na cv. 'Califórnia' após atingir o ponto de máximo, acontece lentamente, diferentemente das outras cultivares que apresentam reduções rápidas, atingido valores próximos de zero no final do ciclo (120 DAP). Segundo Figueiredo (1993), a diminuição dos valores de TCA, depois de atingirem o máximo, ocorre provavelmente como resultado do aumento de estruturas não produtivas, que passam a consumir fotoassimilados da planta.

Na propagação in vitro, as taxas de crescimento absoluto foram, respectivamente, de 10,75, 10,03, 7,98, 6,99 e 6,11 $\mathrm{g}_{\text {planta }}{ }^{-1}$ dia $^{-1}$ para as cultivares 'ESAM 2', 'Branca do Rio de Janeiro', 'Califórnia', 'ESAM 1' e 'ESAM 3', atingidos aos 73, 62, 55, 68 e 66 DAP (Figura 4B). Embora a propagação in vitro tenha aumentado a TCA, a resposta à mesma foi diferente entre as cultivares, pois quando se compara com a propagação convencional, as cultivares 'ESAM 1', 'ESAM 2' e 'ESAM 3' tenderam a ser mais tardias, apesar da colheita de todas cultivares ter sido realizada aos 120 DAP.

Em trabalho realizado por Conceição et al. (2005), a taxa de produção de matéria seca foi crescente até os 90 dias após a transplantação para as cultivares de batata-doce 'Da Costa' e 'Abóbora', declinando posteriormente até ao final do ciclo. Contudo, a cv. 'Da Costa' teve maiores valores do que a 'Abóbora', de forma consistente, até 120 DAT, igualando-se no final da fase de desenvolvimento. Para as cultivares 'Abóbora' e 'Da Costa', as taxas máximas foram de 14,8 e 20,3 $\mathrm{g} \mathrm{m}^{-2} \mathrm{dia}^{-1}$, respectivamente.

Em relação ao tempo, verifica-se que a tendência geral da taxa de crescimento relativo (TCR) é a redução com o desenvolvimento do ciclo da cultura da batata-doce (Figura 4C e 4D). A TCR representa o aumento, em gramas, de massa seca por unidade de material presente, num período de observação. Assim, qualquer incremento ao longo de determinado período estará diretamente relacionado com a massa alcançada ao longo de um intervalo anterior (Silva et al., 2005). O decréscimo da TCR após o ponto de máximo observado para todas as cultivares de batata-doce deve-se, em parte, ao aumento de tecidos não assimiladores (Benincasa, 

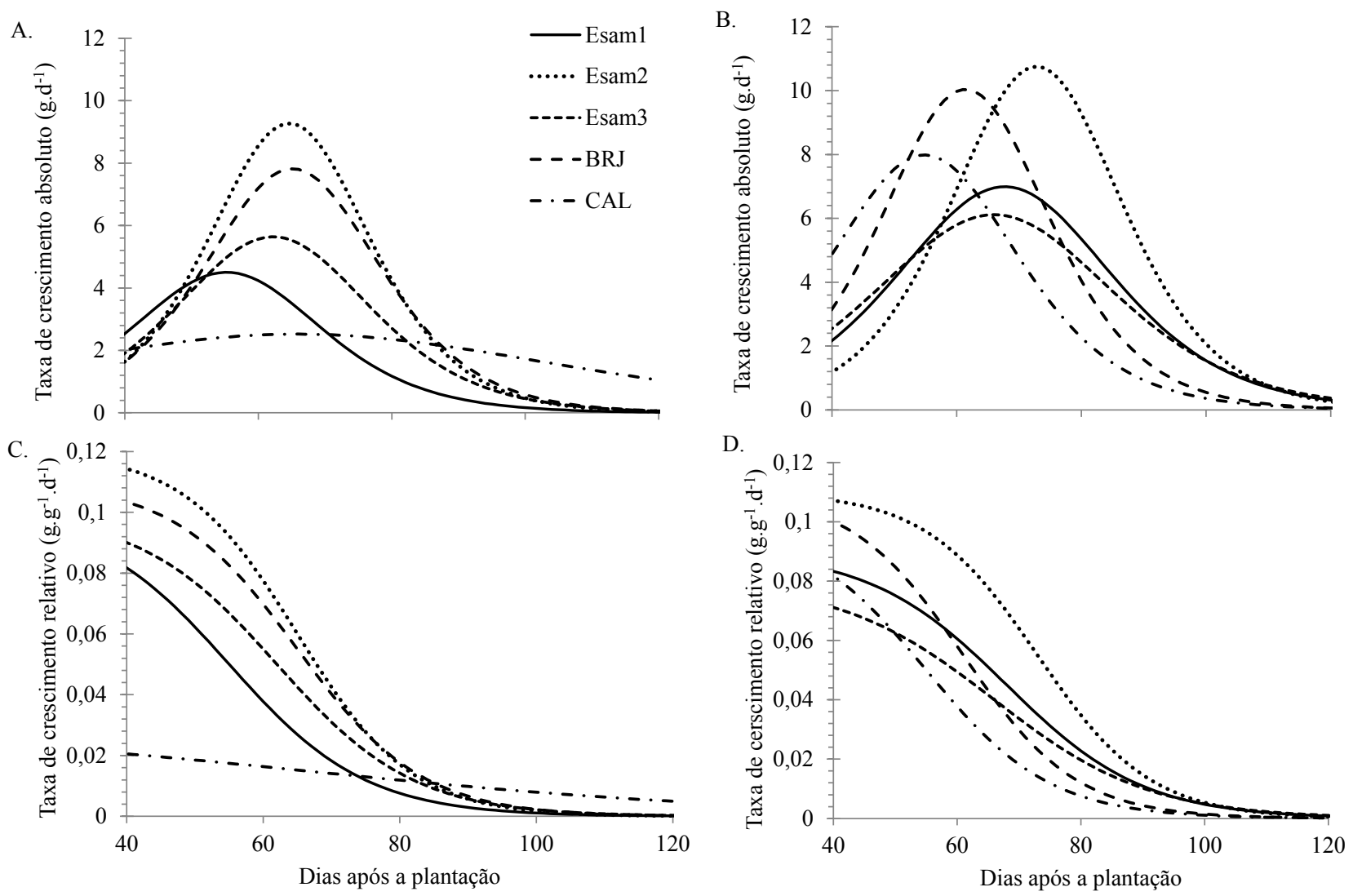

Figura 4 - Taxa de crescimento absoluto (A e B) e taxa de crescimento relativo (C e D) em batata-doce plantada, oriundas de ramas produzidas de forma convencional (A e C) e de cultivo in vitro (B e D), cultivares 'ESAM 1', 'ESAM 2', 'ESAM 3', 'Branca do Rio de Janeiro' e 'Califórnia'.
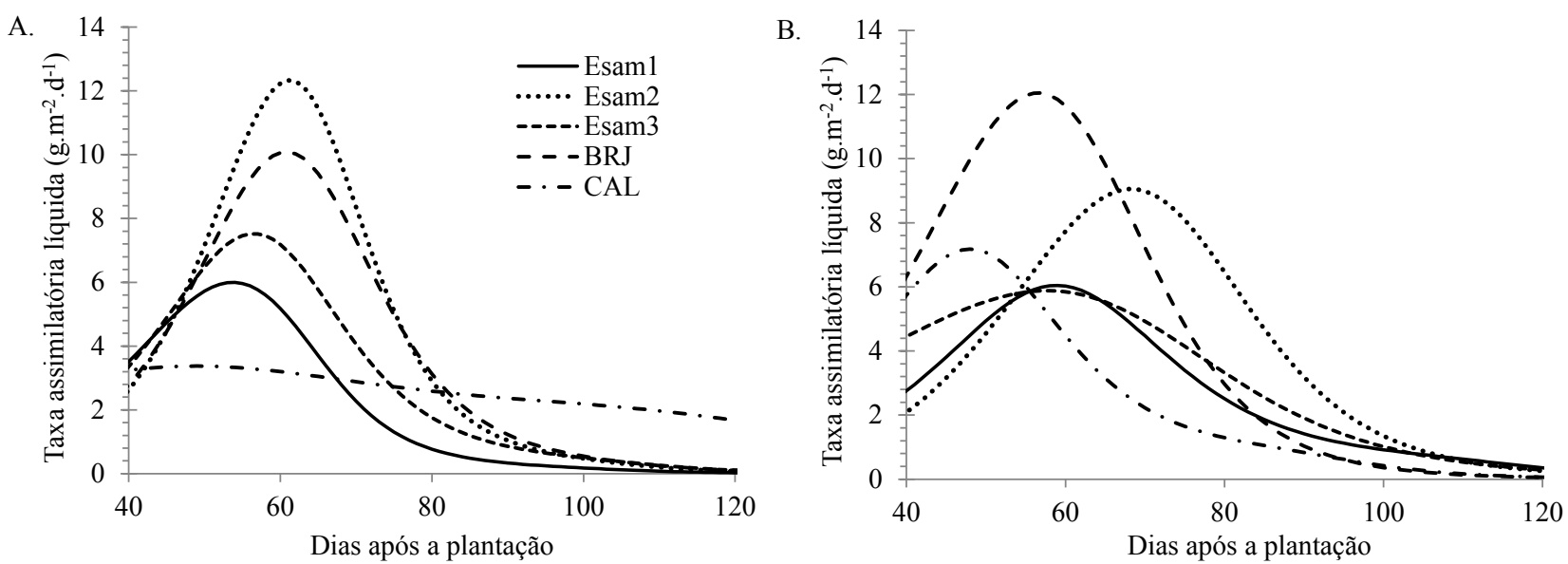

Figura 5 - Taxa assimilatória líquida em batata-doce proveniente da multiplicação convencional (A) e cultivo in vitro (B), cultivares ‘ESAM 1', 'ESAM 2', ‘ESAM 3', ‘Branca do Rio de Janeiro’ e ‘Califórnia'. 
2003). Esse comportamento de TCR é amplamente reportado na literatura, como em Aguiar Neto et al. (2000), Conceição et al. (2005) e Barcelos et al. (2007). Entre as cultivares, a 'Califórnia' apresentou menor TCR e a 'ESAM 2' a máxima.

Houve uma grande variação nos valores de taxa assimilatória líquida obtidos tanto entre cultivares como nas formas de propagação (Figuras 5A e 5B). Observa-se que os valores máximos de TAL tendem a ocorrer em épocas diferentes e que os valores máximos também aparentam ser diferentes.

A taxa assimilatória líquida representa o potencial de produção de massa seca por unidade de área foliar. É um indicador fisiológico, fortemente relacionável com a eficiência fotossintética. Esse índice deve ser avaliado conjuntamente com a razão de área foliar e o conjunto deles usado para explicar a taxa de crescimento relativo (TCR=TAL $\times$ RAF; Evans, 1972). Assim, o maior crescimento relativo da cultivar 'ESAM 2', proveniente da propagação convencional, pode ser explicado por um maior investimento inicial na formação de área foliar
(Figura 3A), mas também por uma boa capacidade fotossintética. Por outro lado, em plantas oriundas da propagação in vitro, a cultivar 'Branca do Rio de Janeiro', apesar do baixo investimento na produção de área foliar (Figura 3B), apresenta alta taxa de assimilação líquida (Figura 5B), sendo a taxa de crescimento relativo semelhante à da cultivar 'ESAM 2' (Figura 4D).

\section{CONCLUSÕES}

As plantas oriundas de cultura de tecidos apresentaram maior crescimento, tanto em massa quanto em área foliar, e maior produção de raízes.

A cultivar 'ESAM 2' produziu maior quantidade de massa seca total, taxa de crescimento absoluto e massa seca de raízes tuberosas.

Para produção de batata-doce recomenda-se a utilização da cultivar "ESAM2" obtida de plantas propagadas in vitro.

\section{REFERÊNCIAS BIBLIOGRÁFICAS}

Aguiar Netto, A.O.; Rodrigues, J.D. \& Pinho, S.Z. (2000) - Análise de crescimento na cultura da batata submetida a diferentes lâminas de irrigação. Pesquisa Agropecuária Brasileira, vol. 35, n. 5, p. 901-907. http:// dx.doi.org/10.1590/S0100-204X2000000500006

Aumonde, T.Z.; Lopes, N.F.; Moraes, D.M.; Peil, R.M.N. \& Pedó, T. (2011) - Análise de crescimento do híbrido de mini melancia Smile ${ }^{\circledR}$ enxertada e não enxertada. Interciencia, vol. 36, n. 9, p. 677-681.

Barcelos, D.M.; Garcia, A. \& Maciel Junior, V.A. (2007) - Análise de crescimento da cultura da batata submetida ao parcelamento da adubação nitrogenada em cobertura, em um latossolo vermelho-amarelo. Ciência e Agrotecnologia, vol. 31, n. 1, p. 21-27. http://dx.doi.org/10.1590/S1413-70542007000100003

Benincasa, M.M.P. (2003) - Análise de crescimento de plantas: noções básicas. 2ํㅡ. ed. FINEP, Jaboticabal, 41 p.

Cavalcanti, F.J.A. (1998) - Recomendações de adubação para o estado de Pernambuco. $2^{\circ}$ ed. Recife, IPA, 198 p.

Conceição, M.K.; Lopes, N.F. \& Fortes, G.R.L. (2005) - Análise de crescimento de plantas de batata-doce (Ipomoea batatas (L.) Lam) cultivares Abóbora e da Costa. Revista Brasileira Agrociência, vol. 11, n. 3, p. 273-278.

Echer, F.R.; Dominato, J.C. \& Creste, J.E. (2009) - Absorção de nutrientes e distribuição da massa fresca e seca entre órgãos de batata-doce. Horticultura Brasileira, vol. 27, n. 2, p. 176-182. http://dx.doi.org/10.1590/ $\underline{\text { S0102-05362009000200010 }}$

Evans, G.C. (1972) - The quantitative analysis of plant growth. University of California Press, Los Angeles, 734 p.

Figueiredo, A.F. (1993) - Armazenamento de ramas, tipos de estacas, profundidade de plantio e análise do crescimento de plantas de batata-doce (Ipomoea batatas (L) Lam.). Tese de Doutoramento. Universidade Federal de Viçosa, Brasil, $127 \mathrm{p}$.

IBGE (2010) - Produção agrícola Mundial - Culturas temporárias e permanentes. Instituto Brasileiro de Geografia e Estatística Ministério do Planejamento, Orçamento e Gestão, Rio de Janeiro, 91 p. 
Larcher, W. (2004) - Ecofisiologia vegetal. 3o ed. São Carlos, Rima, 531 p.

Madeira, N.R; Teixeira, J.B.; Arimura, C.T. \& Junqueira, C.S. (2005) - Influência da concentração de BAP e AG3 no desenvolvimento in vitro de mandioquinha-salsa. Horticultura Brasileira, vol. 23, n. 4, p. 982-985. http://dx.doi.org/10.1590/S0102-05362005000400024

Magalhães, J.S.; Santos, M.D.M.; Cunha Filho, F.N.; Blumer, L.; Guerra, M.P. \& Torres, A. C. (2006) - Indução de embriogênese somática em genótipos de batata doce. Horticultura Brasileira, vol. 24, n. 1, p. 79-83.

Medeiros, J.G.; Pereira, W. \& Miranda, J.E.C. (1990) - Análise de crescimento em duas cultivares de batata-doce (Ipomoea batatas (L.) Lam). Revista Brasileira de Fisiologia Vegetal, vol. 2, n. 2, p. 23-29.

Murashige, T. \& Skoog, F. (1962) - A revised medium for rapid growth and bioassays with tobacco issue cultures. Physiologia Plantarum, vol. 15, n. 3, p. 473-497. http://dx.doi.org/10.1111/j.1399-3054.1962.tb08052.x

Queiroga, R.C.F.; Santos, M.A.; Menezes, M.A.; Vieira, C.P.G. \& Silva, M.C. (2007) - Fisiologia e produção de cultivares de batata-doce em função da época de colheita. Horticultura Brasileira, vol. 25, n. 3, p. 371-374. http://dx.doi.org/10.1590/S0102-05362007000300010

Oliveira, M.K.T.; Neto. F.B.; Câmara, F.A.A.; Dombroski, J.L.D. \& Freitas, R.M.O. (2008) - Multiplicação in vitro de batata-doce (Ipomoea batatas Lam). Revista Caatinga, vol. 21, n. 4, p.129-134.

Resende, F.V.; Gualberto, R. \& Souza, R.J. (2000) - Crescimento e produção de clones de alho provenientes de cultura de tecidos e de propagação convencional. Scientia Agrícola, vol. 57, n. 1, p. 61-66. http://dx.doi. org/10.1590/S0103-90162000000100011

Silva, A.C.; Ferreira, L.R. \& Silva, A.A. (2005) - Growth analysis of Brachiaria brizantha under reduced rates of fluazifop-p-butyl. Planta Daninha, vol. 23, n. 1, p. 85-91. http://dx.doi.org/10.1590/S0100-83582005000100011

Silva, J.B.C.; Lopes, C.A. \& Magalhães, J.S. (2004) - Cultura da batata-doce (Ipomoea batatas L.). EMBRAPA-CNPH, Brasília. n. 6 (Sistema de produção). Versão eletrônica.

Silva, S.O.; Souza, A.S. \& Paz, O.P. (1991) - Efeito da multiplicação vegetativa in vitro na produtividade da batata-doce (Ipomoea batatas L. Lam.). Revista Brasileira de Fisiologia Vegetal, vol. 3, n. 1, p. 47-52.

Souza, M.S.; Alves, S.S.V.; Dombroski, J.L.D.; Freitas, J.D.B. \& Aroucha, E.M.M. (2012) - Comparação de métodos de mensuração de área foliar para a cultura da melancia. Pesquisa Agropecuária Tropical, vol. 42, n. 2, p. 241-245.

Yin, X; Goudriaan, J.; Lantinga, E.A.; Vos, J. \& Spiertz, H.J. (2003) - A flexible sigmoid function of determinate growth. Annals of Botany, vol. 91, n. 3, p. 361-371. http://dx.doi.org/10.1093/aob/mcg029 